\title{
Analysis and Optimization of Passenger Flowlines at Zhongchuan High-Speed Railway Station
}

\author{
Hualan Wang, Baoli Wang, Jiaying Xu $(\mathbb{D}$, and Zunjie Hu \\ Lanzhou Jiaotong University, Lanzhou 730070, China \\ Correspondence should be addressed to Jiaying Xu; 956005349@qq.com
}

Received 4 February 2018; Accepted 13 May 2018; Published 8 July 2018

Academic Editor: Jing-song Hong

Copyright ( 92018 Hualan Wang et al. This is an open access article distributed under the Creative Commons Attribution License, which permits unrestricted use, distribution, and reproduction in any medium, provided the original work is properly cited.

In order to optimize the passenger flowlines and improve the operation capacity of Zhongchuan high-speed railway station, the simulation model of passenger flowlines is established based on the simulation software of Anylogic. The simulation of the passenger flowlines during peak and off-peak hours of the station are carried out respectively. The organization problems of passenger flowlines during peak hours are found out, and the optimization methods are put forward. The station capacity after optimization is compared with the original by employed the simulation model. The result shows, after optimization, although the walking distance of passengers who are entering the ticket hall to buy ticket is increased but the flowline separation effect is achieved, the flowlines become more clear, the cross interferences are reduced, and the station capacity is increased.

\section{Introduction}

In the railway passenger station, due to all kinds of pedestrians, there are different walking routes, which often referred to as passenger flowlines. The passenger flowline is the soul of the railway passenger station. Whether the design and organization of the passenger flowline are reasonable or not, they have an obvious effect on the capacity and the service quality of the passenger station.

Scholars have made a lot of research on the optimization of passenger flowline. The paper was written by Setti and Hutchinson [1] and Takakuwa and Oyama [2] and Zhang et al. [3] qualitatively analyzed the passenger flowlines in passenger terminals, and the methods is used to reduce the traffic problems. In Bohari et al.'s paper [4], the simulation successfully modelled the passenger movement pattern, factors influencing the movement, and the walking speed. In the Hoogendoom and Bovy's literature [5], the pedestrian path selection behavior is discussed, and the pedestrian route and regional selection model based on queuing theory are established. In Hui et al. [6] and Li et al. [7], the appropriated optimization model and algorithm were proposed according to different optimized content and organization goals, and the traffic simulation processes more suitable to regional optimization were designed. In the literatures written by Zhang [8], Xue and Zhang [9], Yin [10], Chen [11], and Chen 2[12], the dynamic simulation of passenger flow is carried out by using the simulation software, and the passenger flow optimization scheme is obtained.In Chen's paper, Anylogic simulation software is used to simulate the transfer space layout, the "bottleneck" of the transfer system is simulated, the transfer system is evaluated intuitively, and the optimization scheme is put forward. In Tang's literature [13], the transfer volume is forecasted and the optimization methods of passenger flowlines are provided. In Chen's literature [14], the facility layout of subway stations are simulated by the Anylogic software, the density and the average walk time of passenger flow under different facility layout are calculated, and a reasonable facility arrangement plan is obtained. Alodhaibi et al.'s study [15] focuses on the passenger flow problem in the airport terminal, and by entering the flight schedules using the simulation framework developed by DES, it is possible to simulate all the flights from curb-side to boarding activity.

All the research literatures about passenger flowlines are focused on the traditional railway stations or urban transport terminals. There is a lack of research on the flowline of the high-speed railway station. Compared with traditional railway 


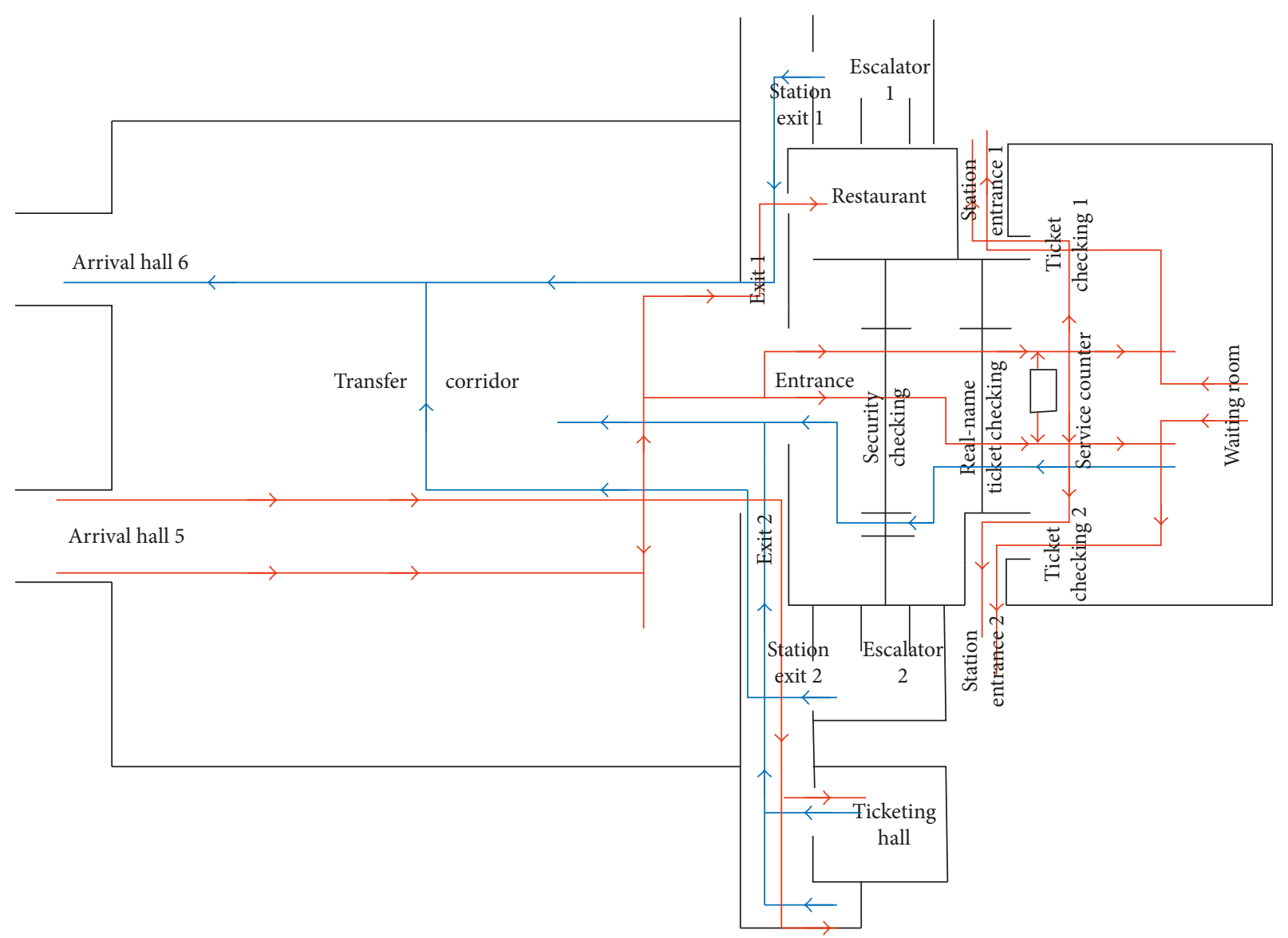

FIGURE 1: Current passenger flowlines of ZC Station. Red lines represent incoming flowlines, and blue lines represent outbound flowlines.

stations, the characteristics of passenger flowlines in highspeed railway stations are different, so the problems and the research key points about its flowlines are different. This paper analyzed the flowlines of Zhongchuan high-speed railway station (ZC Station for short), which is located in Lanzhou, the capital city of Gansu province, and is underground of the Zhongchuan airport. The main object of ZC Station is as transfer terminal for the city to airport passengers. Anylogic simulation software is used to establish the passenger flow simulation model. The simulation of the passenger flowlines in mean period and peak hours of ZC Station are carried out, respectively. We find out the shortcomings of the flowline organization in the peak period and put forward the optimization methods. The Anylogic simulation software is used to compare the original evacuation capacity with the optimized evacuation capacity of ZC Station and then provide the suggestion for the facilities layout and flowline organization.

\section{Analysis of Passenger Flowlines}

ZC Station consists of underground floor and ground floor. The train platforms are located on the underground floor, and the other service facilities such as the ticket room, the waiting room, and security channels are on the ground floor. In order to achieve seamless transfer, the ground floor is connected with T2 terminal of the airport through the transfer corridor.
Passenger activities are frequent in the transfer corridor, and flowlines are complex and prone to cross. So the transfer corridor is most important in flowline research and analysis. The main passenger flowlines in ZC Station include entering flowlines on the ground floor and the exiting flowlines on the underground, as well as the passing flowlines and the waiting flowlines.

Current passenger flowlines of ZC Station are shown in Figure 1.

2.1. Problems of Incoming (Entering) Passenger Flowlines. The main problems of incoming passenger flowlines in ZC Station are as follows:

There are cross interferences between passenger flowlines from Arrival hall 6 of the airport to the train ticket vending machines (TVMs) at the station and passenger flowlines from exit 2 of the station to the airport terminal 2 .

There are cross interferences between passenger flowlines from Arrival hall 6 of the airport to TVMs of the station and passenger flowlines from the station's ticket room to Arrival hall 5 of the airport.

There are cross interferences between passenger flowlines from Arrival hall 6 of the airport to ZC Station's TVMs and passenger flowlines from TVMs to the waiting room of ZC Station. 


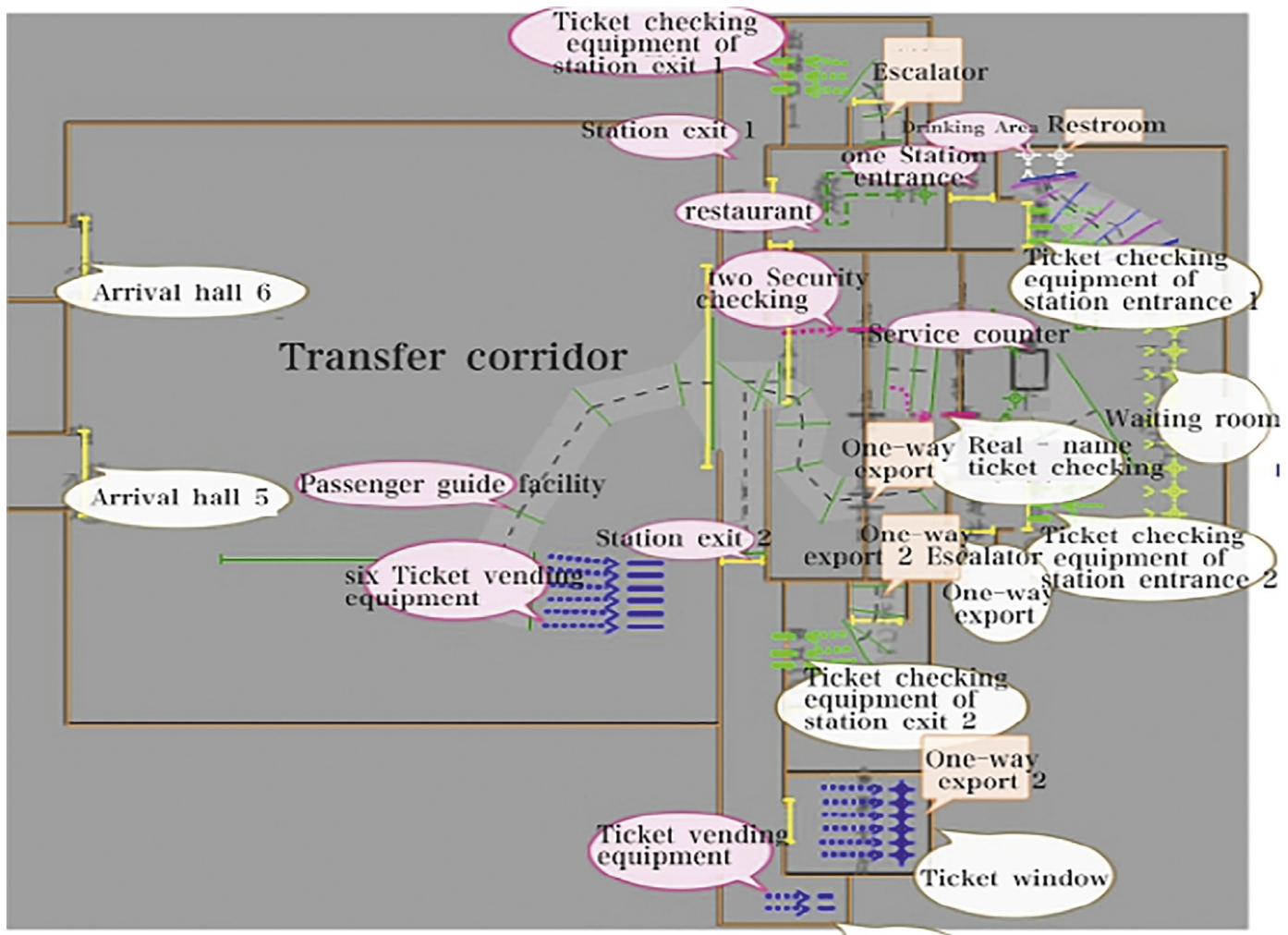

FIGURE 2: Environmental modeling of ZC Station.

There are cross interferences between passenger flowlines from Arrival hall 5 or Arrival hall 6 of the airport to TVMs and passenger flowlines from exit 2 of the station to the transfer corridor.

There are cross interferences between passenger flowlines from Arrival hall 5 or Arrival hall 6 of the airport to TVMs and passenger flowlines from TVMs to the waiting room of ZC Station.

Walking route of the passengers from TVMs to the station waiting room is roundabout.

\subsection{Problems of Passenger Flowlines in the Waiting Room.} The function districts of the waiting room are not clear, it results in passengers' extra walking distance and more cross interferences among passenger flowlines.

There is an exit in waiting room but no special channel for it, so cross interferences have been produced among the passengers who are walking toward the exit and the passengers who are entering the waiting room through the security check gates or the departure passengers who are walking to ticket check gates.

2.3. Problems of Outbound Passenger Flowlines. There are passenger congestion at exit 1 and exit 2 .

The waiting lines before the checking out gates are long when several trains arrived at the same time.

There are cross interferences between outbound passengers from exit 2 and passengers entering the ticket selling room.
There are cross interferences between passenger flowlines from exit 2 of the station to the airport terminal 2 and the passenger flowlines to TVMs at the station.

\section{Passenger Flowline Modeling}

Modeling for passenger flowlines by Anylogic includes environment modeling and behavior modeling: the two parts are independent but associated with each other.

3.1. Environment Modeling. In the modeling process, put the plan of ZC Station drawn by the CAD as a base map into the Anylogic software, and express the wall and other obstacles with the line drawing tool and define them, just like Figure 2 shows. To the service facilities, we need to define their service behavior, time, quantity, waiting queue, and so on. In order to simulate the original performance of the facilities, the pedestrian flows are loaded in a later period. In the simulation process, two processes are shown in one figure, and it can reflect passenger flowline problems more clearly and help us to complete the flowline optimization better.

Due to the different simulation objects, the default parameters and functions of the controls in the software need to be changed, and they are shown in Table 1 .

3.2. Pedestrian Behavior Modeling. We make the pedestrian behavior models for entering flowlines and exiting flowlines, respectively, and they are shown as Figures 3 and 4. 
TABLE 1: Functions and parameters of controls.

\begin{tabular}{lccc}
\hline Control type & Corresponding environmental element & Parameter name & Parameter value \\
\hline PedAreaPescnptor & Escalators or stairs TVM & Movement speed & $0.5 \mathrm{~m} / \mathrm{s}$ \\
PedServices & Ticket window & Delay time & Uniform (2.0, 3.0 s) \\
\hline
\end{tabular}

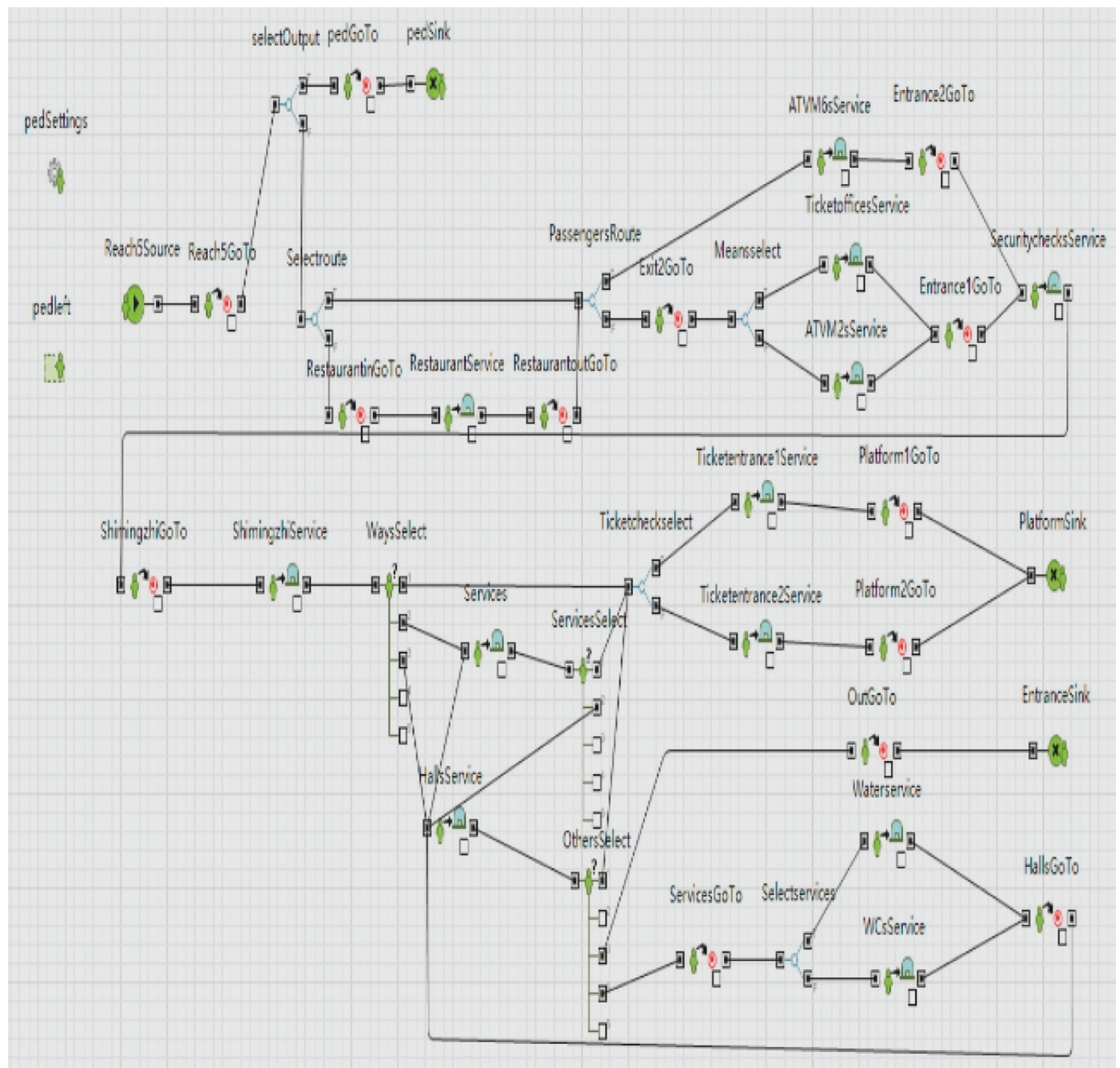

FIGURE 3: The pedestrian behavior of getting in flowlines.

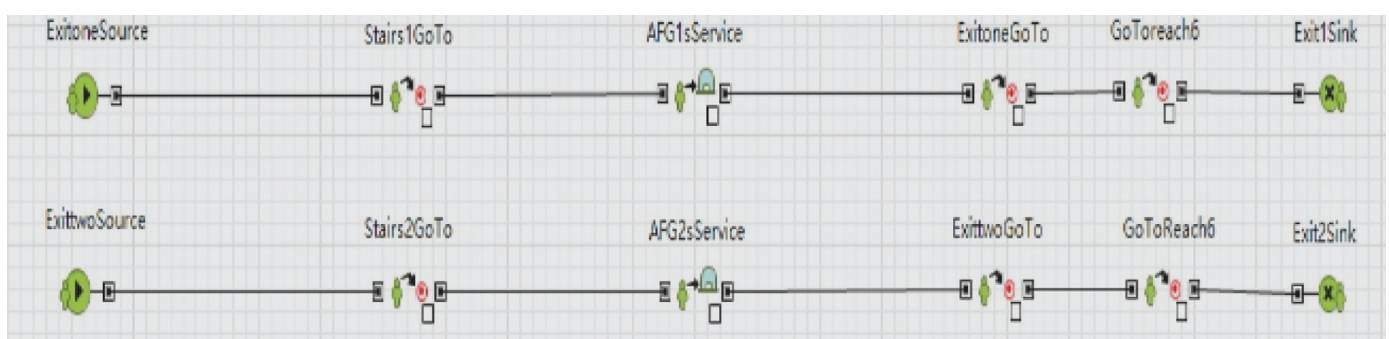

Figure 4: The pedestrian behavior of getting out flowlines.

After completing the pedestrian behavior modeling, environmental model should be adjusted to be consistent with it, so some parameters of the environmental model are defined newly. The important parameters are shown in Table 2.

\section{Passenger Flowline Simulation}

4.1. Passenger Flowline Simulation in Mean Hours. The passenger density of main areas of the station in mean hours 
TABLE 2: Model parameter list.

\begin{tabular}{|c|c|c|c|}
\hline The type of control & Corresponding to environmental elements & Parameter name & Assignment parameters \\
\hline Reach6source & Single passenger & Arrival rate & 3700 person/hour \\
\hline Exitsource & Single passenger & $\begin{array}{c}\text { Arrival rate } \\
\text { Pedestrian diameter }\end{array}$ & $\begin{array}{l}305 \text { person/hour } \\
\text { Uniform }(0.4,0.5 \mathrm{~m})\end{array}$ \\
\hline Pedsource & All passengers & $\begin{array}{c}\text { Initial speed } \\
\text { Comfortable speed }\end{array}$ & $\begin{array}{l}\text { Uniform }(0.3,0.7 \mathrm{~m} / \mathrm{s}) \\
\text { Uniform }(0.5,1 \mathrm{~m} / \mathrm{s})\end{array}$ \\
\hline
\end{tabular}

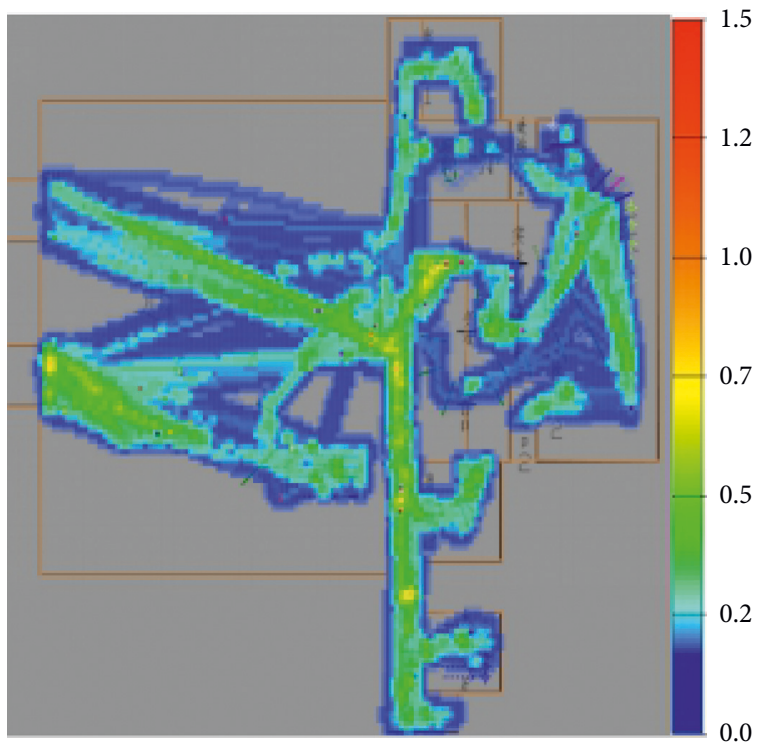

(a)

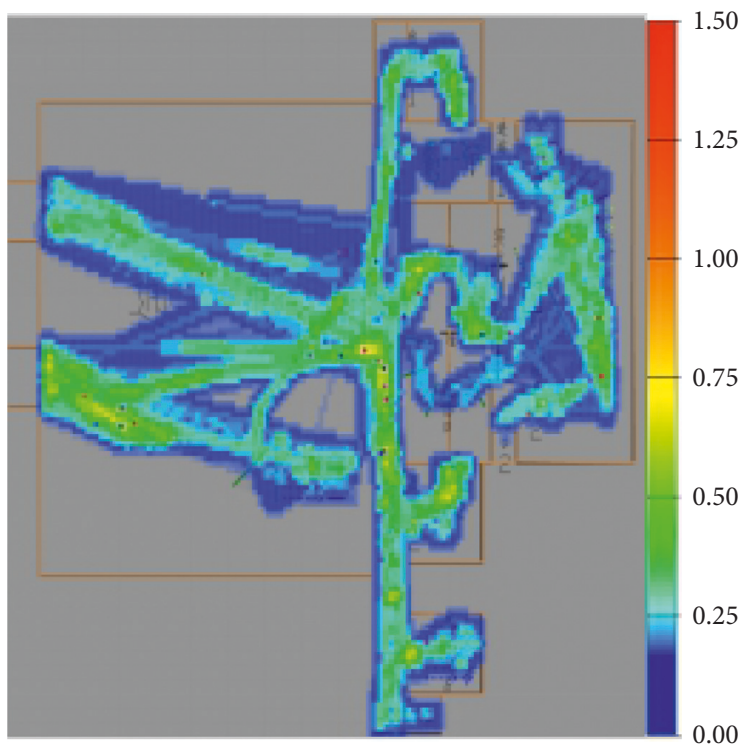

(b)

Figure 5: Passenger density distribution in mean hours. (a) At beginning of the simulation and (b) after some time of the simulation.

can be displayed by the density distribution diagram, and it is shown as Figure 5.

4.1.1. Passenger Flowline Simulation in Peak Hours. Peak hour generally appears in some national holidays, passengers by air will increase fast, the station's passengers will increase rapidly too. The capacities of many facilities in the station cannot meet the demand of large passenger volume. The peak hour density distribution diagram of one day during the Spring Festival transport of 2016 is shown in Figure 6.

\section{Simulation Results Analysis and Passenger Flowline Optimization}

5.1. Simulation Results Analysis. Through the passenger flowline simulation, we can find the following:

In mean hours, the passenger volume is not big, and there has no any congestion in the passenger density distribution diagram. The capacity of the station is rich. Some of the service facilities can be closed to reduce the operating costs.

In peak hours, the passenger volume of the station is very large, and the service capacity of the station is far from the passenger requirements. From Figure 6, we can find that the ticket check channels show congestion when the passengers reach a certain amount. With the passengers increasing, the congestion also produces in the security gates and exit 2 of the station, and it becomes more and more serious as time goes on. It is showed that the capacities of the security gates and the ticket check channels of the station do not satisfy the passenger requirement in the peak hours, and the organization of the passenger flowlines near the exit 2 is not reasonable.

5.2. Flowline Optimization. We analyzed the problems of the station facilities and of the passenger flowlines, provided the following optimization methods:

(1) Add one security gate to improve the security efficiency.

(2) Increase two ticket-check channels to enhance the capacity of ticket check.

(3) Because the ticket hall is located on the north side of the station exit 2, there are interferences among the passengers who are walking to or out of the ticket hall and the passengers exiting from exit 2 . We proposed that the places of the exit 2 and the ticket hall should be exchanged and two doors in the ticket hall should be opened to reduce the flowline cross.

(4) Remove two TVMs at the door out of the ticket hall to other places in order to avoid the congestion around exit 2.

(5) At present, Arrival hall 5 and Arrival hall 6 of the airport are the passenger flowlines from the airport 

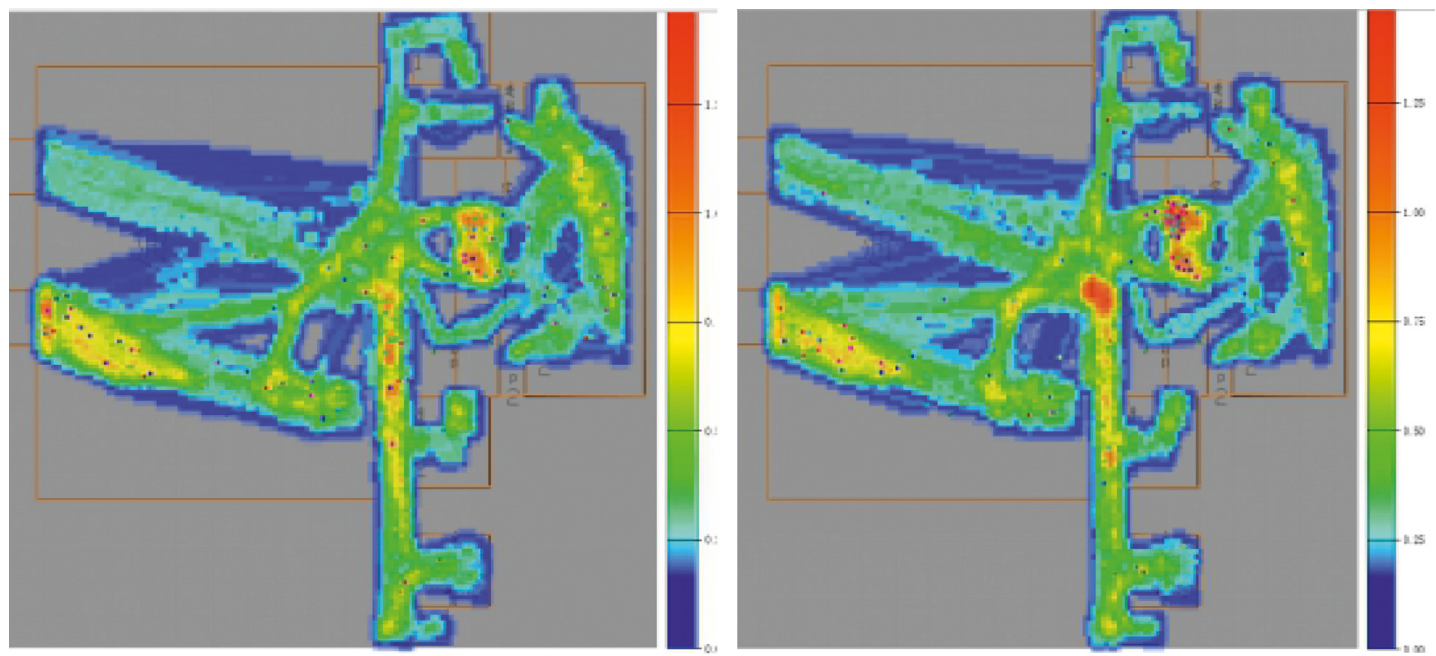

(a)
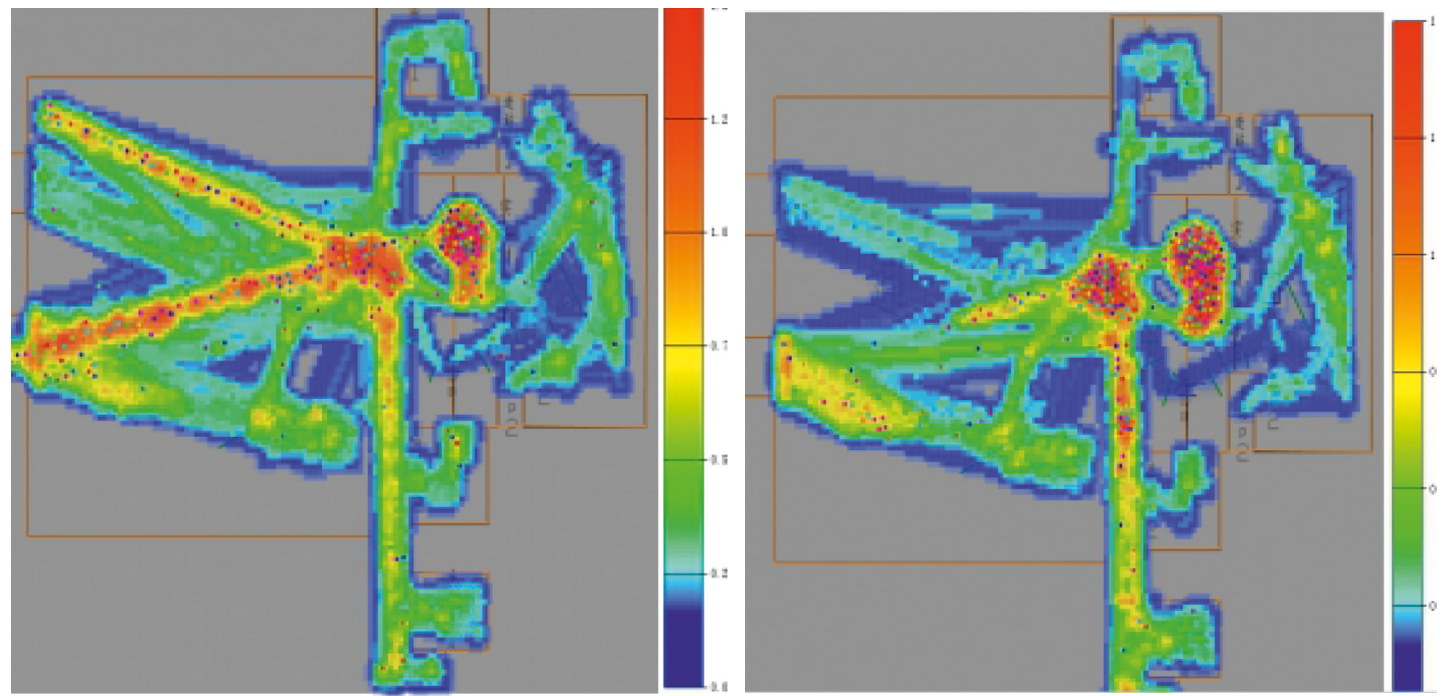

(b)
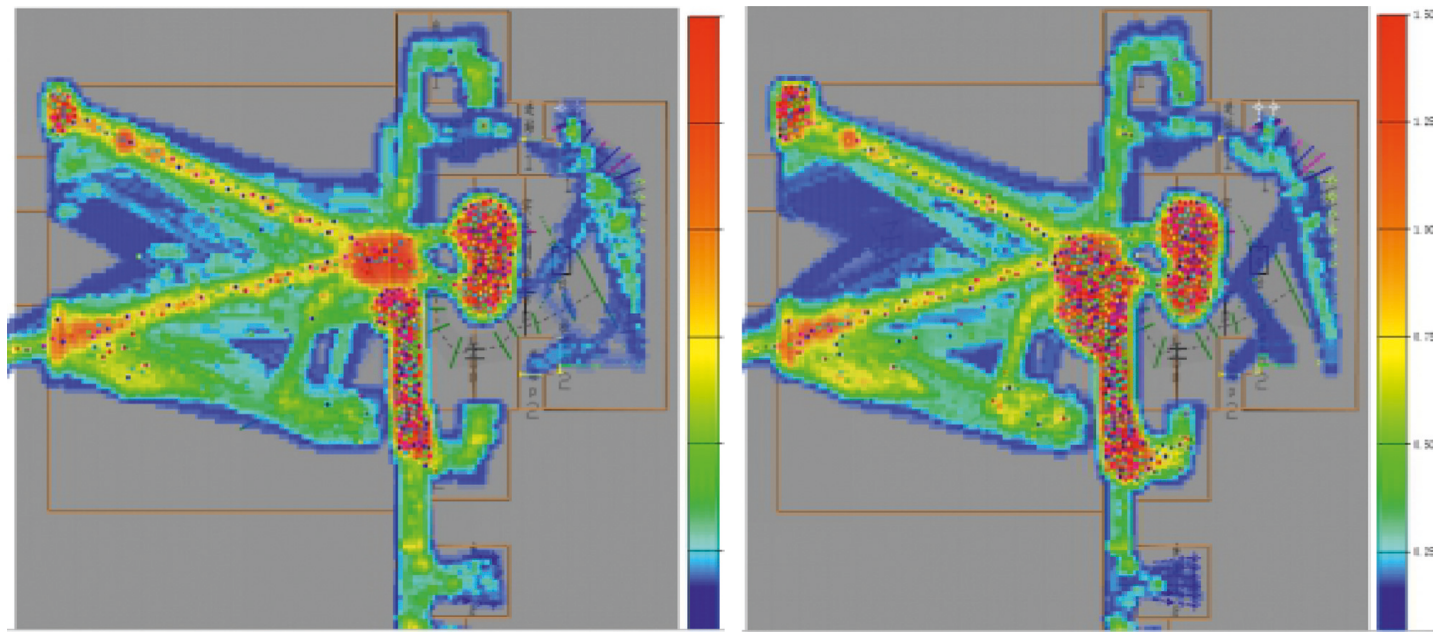

(c)

FIGURE 6: Passenger density distribution in peak hour. (a) The beginning of simulation, (b) the middle of the simulation, and (c) the end of the simulation. 


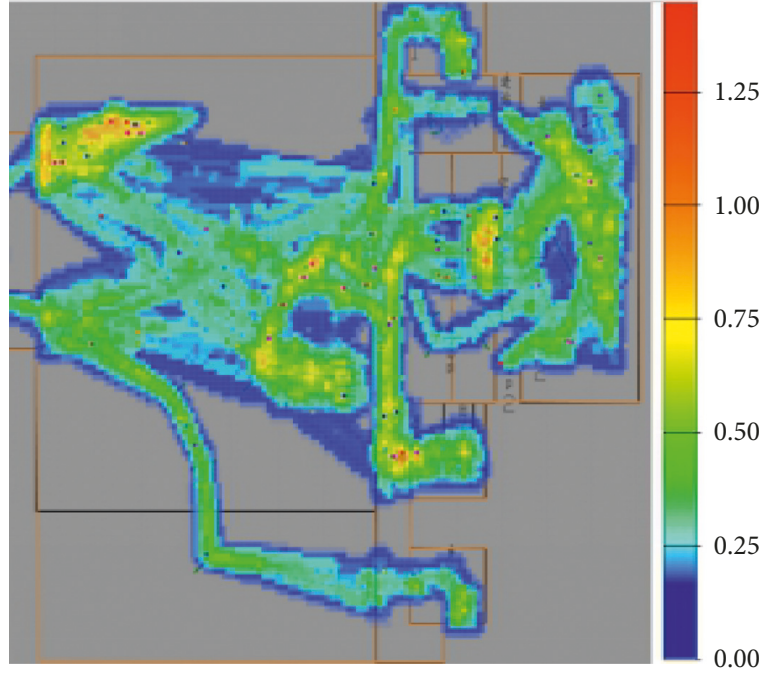

(a)

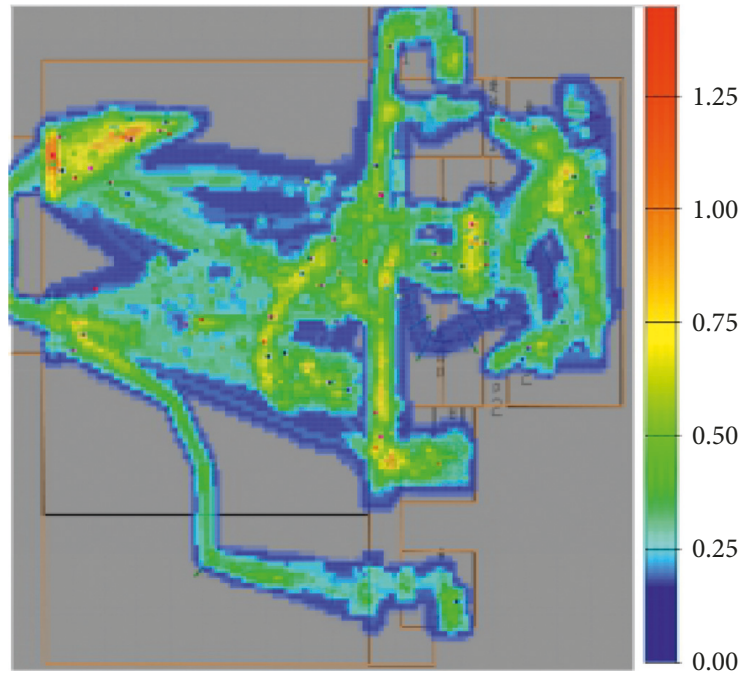

(b)

FIgURE 7: Passenger densities in peak hours after optimization. (a) The beginning of simulation and (b) middle moment of simulation.

to the station and from the station to the airport, respectively. We can exchange the entrances and exits to reduce interference on transfer channel.

The passenger densities in peak hours after optimization are shown in Figure 7.

The simulation results show that the distance of passengers to the ticket hall has been increased, but the effect of passenger flow separation has been achieved, and the cross interferences of passenger flowlines are reduced. The obvious benefits are that the total time of passengers' stay in the station will be greatly cut down, the evacuation capacity of the station will be improved, and all this makes the station's operating efficiency increased significantly.

\section{Conclusions}

(1) We analyze the current passenger flowlines of ZC Station and draw the passenger flowline chart. From the flowline chart, we find there are problems such as cross interferences among the passenger flowlines and the congestions in some points of the station.

(2) The simulation model of the passenger flowline of ZC Station is established using the software of Anylogic. Flowlines in peak hours and in mean period of ZC Station are simulated. The result shows the station capacity has a certain surplus in mean hours. In peak hours, the capacities of the security gates and ticket-check channels are obviously insufficient, and there are many cross interferences among the passenger flowlines around exit 2.

(3) We provide the optimization methods for passenger flowlines and make the optimization simulation. After optimization, the cross interferences of passenger flowlines are reduced, the total time of passengers' stay in the station is cut down, the congestions disappear and the evacuation capacity of the station is improved.
(4) In the simulation, we do not consider the impact of static pedestrians, persons without fixed goals, and working persons to the passenger flowlines, and these should be further researched.

\section{Data Availability}

The authors do not intend to share the specific survey data in the paper, but the data mentioned in the text are available from the corresponding author upon request.

\section{Conflicts of Interest}

The authors declare that they have no conflicts of interest.

\section{Acknowledgments}

This work was supported by the National Natural Science Foundation of China (51468035).

\section{References}

[1] J. R. Setti and B. G. Hutchinson, Passenger Terminal Simulation Model, Metropolitan Association of Uthan Designers and Environmental Planners, New York, NY, USA, 1971.

[2] S. Takakuwa and T. Oyama, "Simulation analysis of international-departure passenger flows in an airport terminal," Transportation Science, vol. 1, pp. 26-30, 1998.

[3] H. Zhang, Y. Xu, L. Yang, and H. Liu, "Macroscopic model and simulation analysis of air traffic flow in airport terminal area," Discrete Dynamics in Nature and Society, vol. 2014, Article ID 741654, 15 pages, 2014.

[4] Z. A. Bohari, S. Bachok, and M. M. Osman, "Improving the quality of public transportation system: application of simulation model for passenger movement," Procedia-Social and Behavioral Sciences, vol. 153, pp. 542-552, 2014.

[5] S. P. Hoogendoom and P. H. L. Bovy, "Pedestrian routechoice and activity scheduling theory and models," 
Transportation Research Part B: Methodological, vol. 38, no. 2, pp. 169-190, 2004.

[6] M. Hui, L. Bai, Y. Li, and Q. Wu, "Highway traffic flow nonlinear character analysis and prediction," Mathematical Problems in Engineering, vol. 2015, Article ID 902191, 7 pages, 2015.

[7] S.-B. Li, G.-M. Wang, T. Wang, and H.-L. Ren, "Research on the method of traffic organization and optimization based on dynamic traffic flow model," Discrete Dynamics in Nature and Society, vol. 2017, Article ID 5292616, 9 pages, 2017.

[8] S. Zhang, Study on the Model and Method of Passenger Flow Line Optimization for Large Passenger Station, Beijing Jiaotong University, Beijing, China, 2010.

[9] Y. Xue and X. Zhang, "Optimization analysis of passenger flow organization in Beijing south railway station based on Anylogic simulation technology," Railway Computer Applications, vol. 2, no. 21, pp. 5-8, 2012.

[10] Y. Yin, Design and Optimization of large Passenger Flow Line in Subway Station, Xinan Jiaotong University, Chengdu, China, 2013.

[11] J. Chen, Study on Urban Rail Transit Simulation of Chengdu North Station Based on Anylogic, Southwest Jiaotong University, Chengdu, China, 2014.

[12] L. Chen, Simulation Research of Urban Rail Transit Station Based on Anylogic, Chang'an University, Xi'an, China, 2015.

[13] Z. Tang, Flowline Organization and Analysis of Integrated Passenger Hub, Xinan Jiaotong University, Chengdu, China, 2010.

[14] L. Chen, "Simulation study on layout of subway station level facilities based on Anylogic," Traffic Information and Security, vol. 5, no. 31, pp. 19-24, 2013.

[15] S. Alodhaibi, R. L. Burdett, and P. K. D. V. Yarlagadda, "Framework for airport outbound passenger flow modelling," Procedia Engineering, vol. 174, pp. 1100-1109, 2017. 


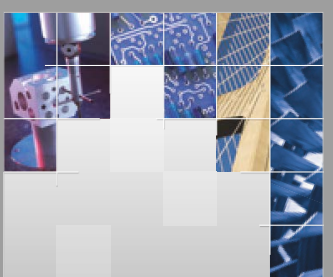

\section{Enfincering}
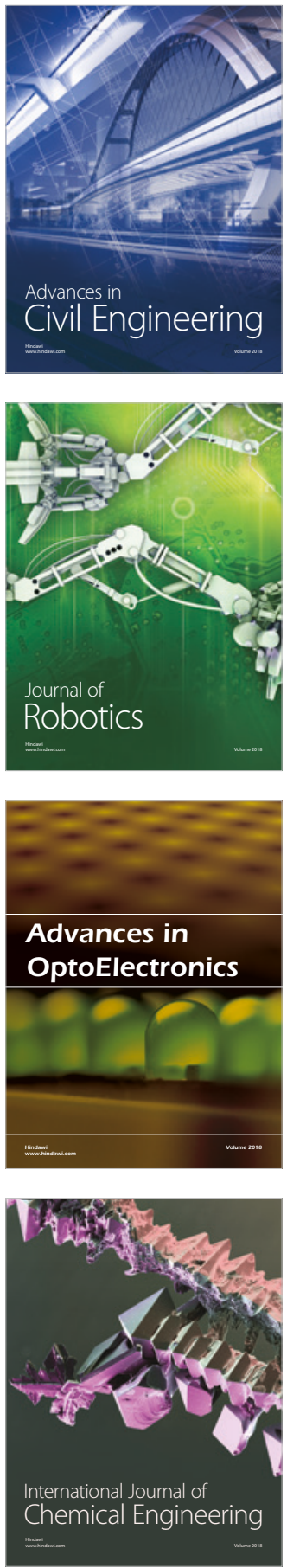

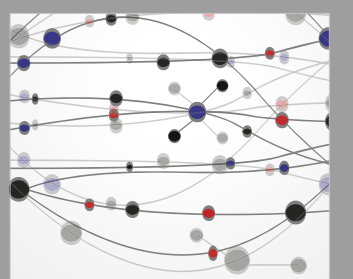

\section{Rotating \\ Machinery}

The Scientific World Journal

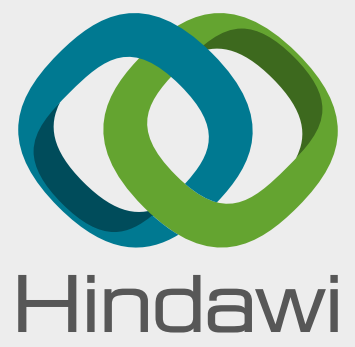

Submit your manuscripts at

www.hindawi.com
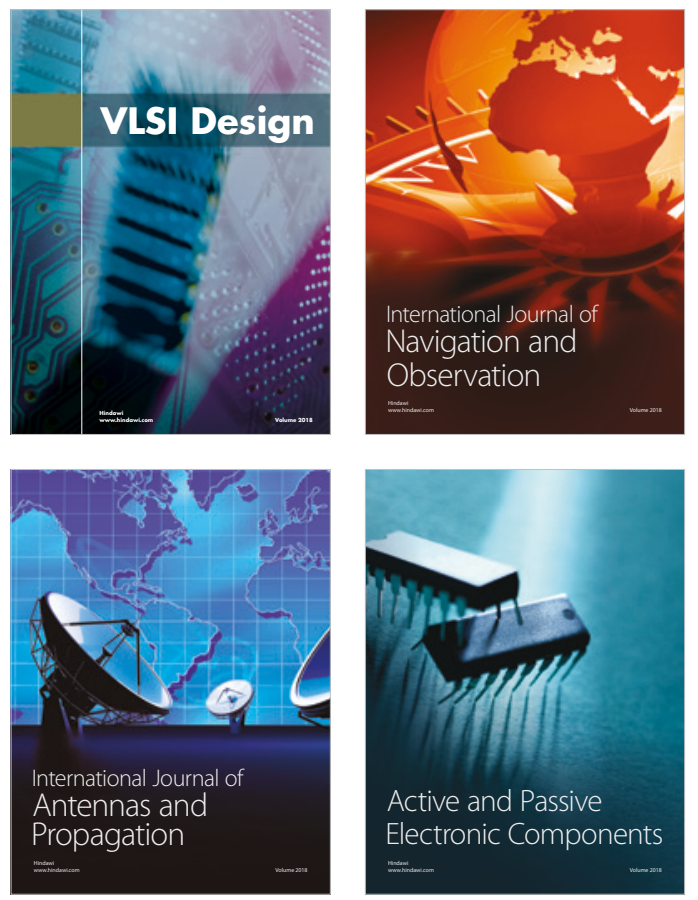
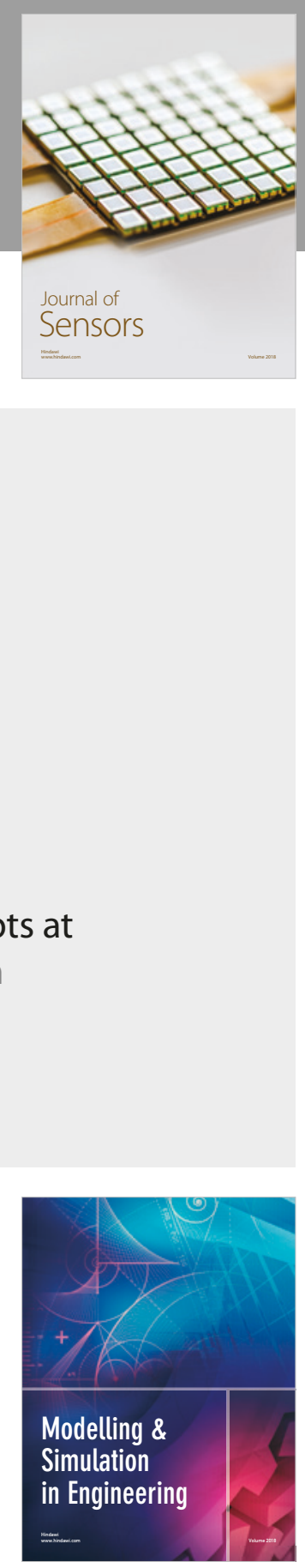

\section{Advances \\ Multimedia}
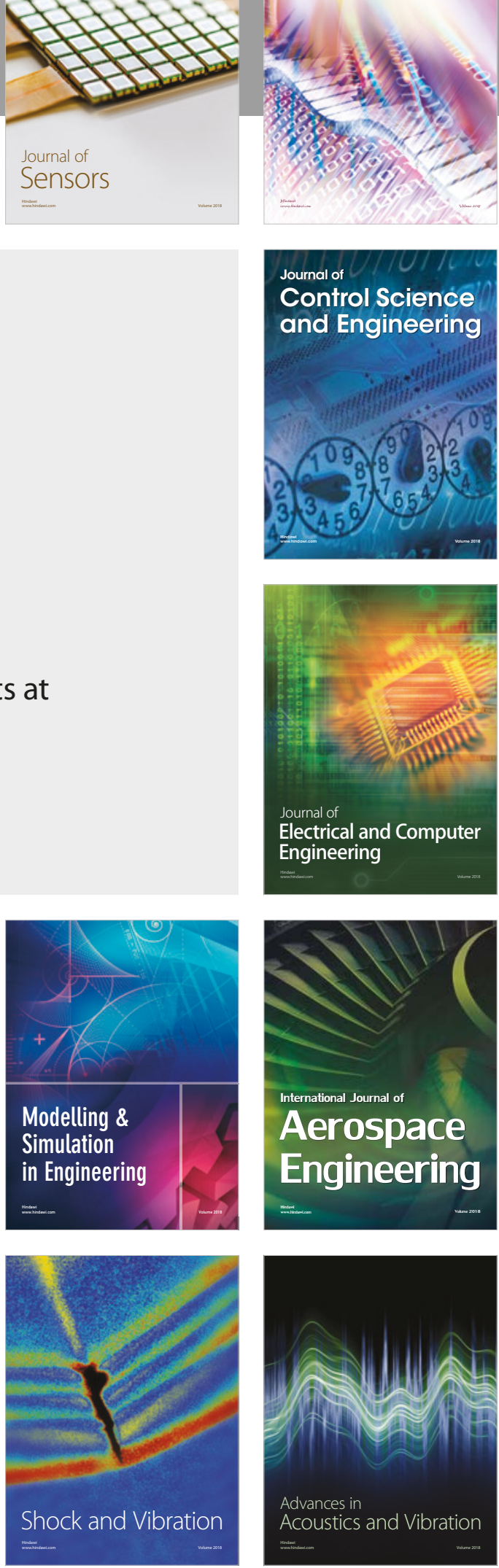